\title{
Método eletroforético rápido para detecção da adulteração do leite caprino com leite bovino
}

[Fast electrophoretic detection method of adulteration of caprine milk by bovine milk]

\author{
A.S. Egito ${ }^{1}$, G.M.S. Rosinha ${ }^{1}$, L.E. Laguna ${ }^{1}$, L. Miclo², J.M. Girardet ${ }^{2}$, J.L. Gaillard ${ }^{2}$ \\ ${ }^{1}$ Laboratório de Tecnologia de Leite, Embrapa Caprinos \\ Caixa Postal D-10 \\ 62011-970 - Sobral, CE \\ ${ }^{2}$ Unité de Recherche sur l'Animal et Fonctionnalités dês Produits Animaux (URAFPA), Nancy-Université
}

\begin{abstract}
RESUMO
Avaliaram-se os métodos de eletroforese em gel de poliacrilamida (PAGE) em presença de uréia (uréiaPAGE) e dodecil sulfato de sódio (SDS-PAGE) para identificar a adulteração do leite de cabra pela adição do leite de vaca. Um método foi otimizado para preparação do caseinato de sódio em poucos minutos para análise eletroforética. Uréia-PAGE foi o método mais apropriado para identificação desse tipo de fraude, em decorrência da presença da caseína $\alpha_{\mathrm{s} 1}$ com migração mais rápida no leite bovino. A presença da $\alpha_{\mathrm{s} 1}$-caseína bovina foi detectada a partir da adição de $2,5 \%$ de leite de vaca utilizando uréiaPAGE. O limite de detecção, a repetibilidade, o tempo para execução indicaram que esse método pode ser aplicado como rotina no controle de qualidade do leite de cabra recebido pelas indústrias de processamento.
\end{abstract}

Palavras-chave: leite, cabra, vaca, adulteração, caseína, eletroforese

\begin{abstract}
Polyacrylamide gel electrophoresis (PAGE) in presence of urea (urea-PAGE) or sodium dodecyl sulfate (SDS-PAGE) was evaluated to detect the presence of cow milk added to goat milk. A method was optimized to prepare sodium caseinate from milk in few minutes. After that, the sodium caseinate was analyzed by PAGE. The urea-PAGE was the most appropriated method to identify adulteration as caprine and bovine $\alpha_{s 1}$-caseins displayed different migration rates. When cow milk was added to goat milk at different proportions, the presence of bovine $\alpha_{s 1}$-casein was detected in the mixture by ureaPAGE for a minimal proportion of $2.5 \%$ of cow milk added to goat milk. The good sensitivity, the repeatability and the short time for execution indicate that the described method will be able to be routinely applied for the quality control of goat milk in dairy industry.
\end{abstract}

Keywords: milk, goat, cow, adulteration, casein, electrophoresis

\section{INTRODUÇÃO}

A qualidade dos alimentos tornou-se um problema mundial. É cada vez mais importante detectar a introdução no mercado de produtos rotulados de forma fraudulenta e de qualidade inferior, por razões econômicas e por razões de saúde pública.

As flutuações sazonais na disponibilidade do leite de algumas espécies, como o de cabra e de ovelha, além do preço mais elevado em relação

Recebido em 26 de abril de 2005

Aceito em 2 de maio de 2006

E-mail: egito@cnpc.embrapa.br 
ao de vaca, são um incentivo para que esse produto seja adulterado com leite de maior disponibilidade e menor preço. No Brasil, tem-se observado esse tipo de adulteração no leite de cabra. Desse modo, a possibilidade de determinar a qualidade do leite entregue no laticínio, que será utilizado para o consumo in natura ou na produção de derivados lácteos caprinos, tem grande importância. Assim, por razões éticas e econômicas, torna-se imperativo desenvolver métodos sensíveis para a detecção de outros tipos de leite em produtos lácteos originados do leite de cabra.

Nos últimos anos, foram desenvolvidos vários métodos analíticos para detecção de misturas de leite de diferentes espécies. Entre esses métodos destacam-se os baseados na análise das frações protéicas, dos quais os principais são os métodos cromatográficos, eletroforéticos, imunológicos e a reação em cadeia da polimerase (PCR). Cromatografia líquida em fase reversa (reversedphase high pressure liquid chromatography RP-HPLC) e cromatografia por fast protein liquid chromatography (FPLC) foram usadas para separar proteínas do soro de leite de várias espécies (Pellegrino et al., 1991; Laezza et al., 1991). A separação das caseínas bovina, ovina e caprina, usando vários procedimentos de HPLC e FPLC, também foi usada por Law e Tziboula (1992), Law et al. (1992) e Kaminarides e Anifantakis (1993).

Vários estudos foram realizados utilizando análises eletroforéticas da mistura de leite de varias espécies através da caseína $\alpha_{\mathrm{S} 1}$ (Cattaneo et al., 1996), caseína $\beta$ (Mayer e Hortner, 1992) e caseína $\gamma$ (Addeo et al., 1990). A detecção de proteínas de leite utilizando ELISA foi proposta para a detecção do leite de vaca adicionado ao leite de ovelha e de cabra na fabricação de queijos (Anguita et al., 1995; Anguita et al., 1996; Rolland et al., 1995). Recentemente, a técnica de PCR, que se baseia na análise do DNA, aplicada na indústria láctea para detectar a presença de leite de vaca em queijos fabricados com leite de cabra (Maudet e Taberlet, 2001), mostrou ser um método bastante promissor em decorrência de sua alta sensibilidade.

Na União Européia, utiliza-se como método de referência para detectar caseína bovina em queijos fabricados com leite caprino, ovino e bubalino a focalização isoelétrica (IEF-
Isoelectric focusing) da caseína $\gamma$ (Reference..., 1996). No Brasil, até o momento, nenhum método oficial foi validado para detecção de fraude do leite de cabra com o leite de vaca, apesar da importância do leite de cabra para crianças e idosos que apresentam problemas de digestibilidade ou alergia ao leite de bovino.

O presente trabalho propos identificar e adaptar métodos eletroforéticos a serem utilizados na detecção de possíveis fraudes do leite de cabra pela adição de leite de vaca. Os métodos foram estudados visando a definição de um protocolo com alta sensibilidade e detecção específica da caseína $\alpha_{\mathrm{S} 1}$ do leite bovino, diminuindo, ao máximo, o tempo de análise.

\section{MATERIAL E MÉTODOS}

A preparação do caseínato de sódio foi realizada segundo o método tradicional utilizado por Egito et al. (2001a, 2002). Amostras de leite, após coletadas, foram imediatamente acondicionadas e mantidas a $-20^{\circ} \mathrm{C}$ até o momento do uso. $\mathrm{O}$ leite foi desnatado por centrifugação $(2100 \mathrm{x} \mathrm{g}$ por $30 \mathrm{~min}$. a $32^{\circ} \mathrm{C}$ ) e a caseína total foi preparada mediante precipitação isoelétrica em $\mathrm{pH}$ 4,2 com $1 \mathrm{M}$ de $\mathrm{HCl}$ para a caseína eqüina e $\mathrm{pH}$ 4,6 para as demais espécies, sendo o precipitado obtido pela centrifugação a 1500 x g por $20 \mathrm{~min}$, a $32^{\circ} \mathrm{C}$. O precipitado foi lavado três vezes com água destilada contendo $0,05 \%$ (v/v) de tolueno, solubilizado ao $\mathrm{pH} 7,0$ através da adição de $1 \mathrm{M}$ de $\mathrm{NaOH}$. Esse ciclo de precipitação-lavagem-dissolução repetiu-se duas vezes. O precipitado de caseína foi solubilizado a pH 7,0 com $1 \mathrm{M}$ de $\mathrm{NaOH}$, e dializado com água deionizada, em presença de timol a $4^{\circ} \mathrm{C}$, por $72 \mathrm{~h}$. A solução de caseína foi liofilizada e estocada a $4^{\circ} \mathrm{C}$. Para obtenção de caseinato do leite de vaca adicionado ao de cabra, precipitou-se o leite a $\mathrm{pH}$ 4,2 com $1 \mathrm{M}$ de $\mathrm{HCl}$, seguida de centrifugação a $1500 \mathrm{x} \mathrm{g}$ por $5 \mathrm{~min}$, a $32^{\circ} \mathrm{C}$. Ao precipitado adicionou-se água destilada e homogeneizou-se por vortex durante 5min, seguida de nova centrifugação a $1500 \times \mathrm{g}$ por $5 \mathrm{~min}$ a $20^{\circ} \mathrm{C}$. O precipitado foi imediatamente preparado para realização das eletroforeses.

Para a avaliação do perfil eletroforético das caseínas das diferentes espécies pelos métodos 
de uréia-PAGE e SDS-PAGE, utilizou-se um aparelho para eletroforese vertical ${ }^{1}$. Para uréiaPAGE, o procedimento foi o recomendado por Sanogo et al. (1989), com 8,2\% de poliacrilamida em $75 \mathrm{mM}$ de Tris- $\mathrm{HCl}$ e $\mathrm{pH} 8,9$ na presença de $4 \mathrm{M}$ de uréia. As amostras $(2 \mathrm{mg} / \mathrm{ml})$ foram incubadas à temperatura ambiente por $1 \mathrm{~h}$ (para solubilização) em $75 \mathrm{mM}$ de Tris-HCL, pH 8,9, contendo 4M de uréia, $5 \%$ de $\beta$-mercaptoetanol, $10 \%$ de glicerol, e $0,01 \%$ de azul de bromofenol. Volumes de $20 \mu \mathrm{l}$ de amostras foram depositados no gel para análise eletroforética.

A SDS-PAGE foi realizada mediante géis de poliacrilamida com concentração de $4,9 \%$ em $125 \mathrm{mM}$ de tampão Tris-HCl, $\mathrm{pH}$ 6,8 e com géis de separação com $15,4 \%$ de poliacrilamida em $380 \mathrm{mM}$ de tampão Tris-HCl, $\mathrm{pH} 8,8$, contendo $0,1 \%$ de SDS (Laemmli e Favre 1973). As amostras $(2 \mathrm{mg} / \mathrm{ml})$ foram dissolvidas em tampão Tris-HCl, $\mathrm{pH} 6,8$, na presença de $0,1 \%$ de SDS e $5 \%$ de $\beta$-mercaptoetanol. Em seguida foram aquecidas a $100^{\circ} \mathrm{C}$ por $3 \mathrm{~min}$, e volumes de $20 \mu \mathrm{l}$ foram depositados nos géis.

Em ambos os tipos de eletroforese, após a corrida, as proteínas foram fixadas no gel com $12 \%$ de ácido tricloroacético (TCA) durante 30 min e, em seguida, coradas com $0,1 \%$ de azul de Coomassie R250, dissolvido em uma mistura de $50 \%$ de etanol e $2 \%$ de TCA, durante $120 \mathrm{~min}$. A descoloração foi realizada durante uma noite com uma solução a $30 \%$ de etanol e $7,5 \%$ de ácido acético.

Para avaliar a presença do leite de vaca no leite de cabra, utilizou-se um sistema de eletroforeses para mini-géis ${ }^{2}$. Os géis foram preparados nas mesmas proporções do utilizado para uréiaPAGE. Simulações da adulteração de amostras foram preparadas a partir da mistura de $0,0,5 ; 1$; 2,$5 ; 5 ; 10 ; 25$ e $100 \%$ de leite de vaca adicionado ao leite de cabra. A caseína obtida foi dissolvida em tampão de amostra contendo $75 \mathrm{mM}$ de TrisHCL, pH 8,9, 4M de uréia, $5 \%$ de $\beta$ mercaptoetanol, $10 \%$ de glicerol e $0,01 \%$ de azul de bromofenol na proporção de $40 \mathrm{mg} / \mathrm{ml}$. Volumes de $5 \mu \mathrm{l}$ foram depositados nos géis.

\footnotetext{
${ }^{1}$ Modelo 2001 - Amersham-Pharmacia, Uppsala, Suécia

${ }^{2}$ Miniprotean II-Electrophoresis cel system (BIO-RAD)
}

Após a corrida, os géis foram corados durante cinco minutos em $0,1 \%$ de azul de Coomassie R250, dissolvidos em uma mistura de $50 \%$ de etanol e $2 \%$ de ácido tricloro acético (TCA), e aquecidos em microondas por três minutos. A descoloração foi feita mediante lavagens com uma solução a $30 \%$ de etanol e $7,5 \%$ de ácido acético, aquecida em microondas.

\section{RESULTADOS E DISCUSSÃO}

Na fig. 1 mostra-se o protocolo para a obtenção do caseínato de sódio utilizado para separação das caseínas das diferentes espécies (via A) e para a detecção de fraude do leite de cabra com leite de vaca, por meio da otimização do método de preparação do caseinato (via B). Vários trabalhos, realizados para separação da caseína do leite (Molina et al., 1999; 2000) e dos queijos (HerreroMartinez et al., 2000) para a detecção de fraude pela adição do leite de outra espécie, apresentavam um protocolo extremamente lento na preparação das amostras (caseínas) em decorrência da utilização de várias lavagens, diálises e liofilizações, (Fig. 1, via A) o que pode durar vários dias. Com o novo método (Fig. 1, via B), utilizando-se em protocolo mais rápido, observouse que a proteína de interesse, no caso a $\alpha_{\mathrm{S} 1}$-caseína, que seria a marcadora para esse tipo de fraude, foi facilmente identificada. Assim, esse protocolo foi o mais indicado por reduzir o tempo de extração dessas proteínas de aproximadamente $96 \mathrm{~h}$ para $1 \mathrm{~h}$, sem afetar significativamente a resolução da caseína $\alpha_{\mathrm{S} 1}$ bovina.

O perfil eletroforético das caseínas do leite de cabra parece ser mais complexo que o de leite humano, de vaca e de camela, com diferenças sensíveis nas migrações eletroforéticas entre bandas (Fig. 2A). No caso do leite de vaca e de camela observa-se uma banda da caseína $\alpha_{\mathrm{S} 1} \mathrm{e}$ uma banda da caseína $\beta$, enquanto no de outras espécies, várias bandas caracterizam cada uma das duas caseínas. Esse é o caso das caseínas do leite de égua, em que, duas zonas de bandas bem distintas caracterizam as caseínas $\alpha_{\mathrm{S} 1}$ e $\beta$, como mostraram Visser et al. (1982) e Egito et al. (2002). No caso do leite humano, a $\alpha_{\mathrm{S} 1}$-caseína apresenta-se em pequena quantidade com relação à $\beta$-caseína. Estes resultados estão de acordo com as dosagens de imunonefelometria realizadas nas caseínas humanas por Montagne et al. (2000). 


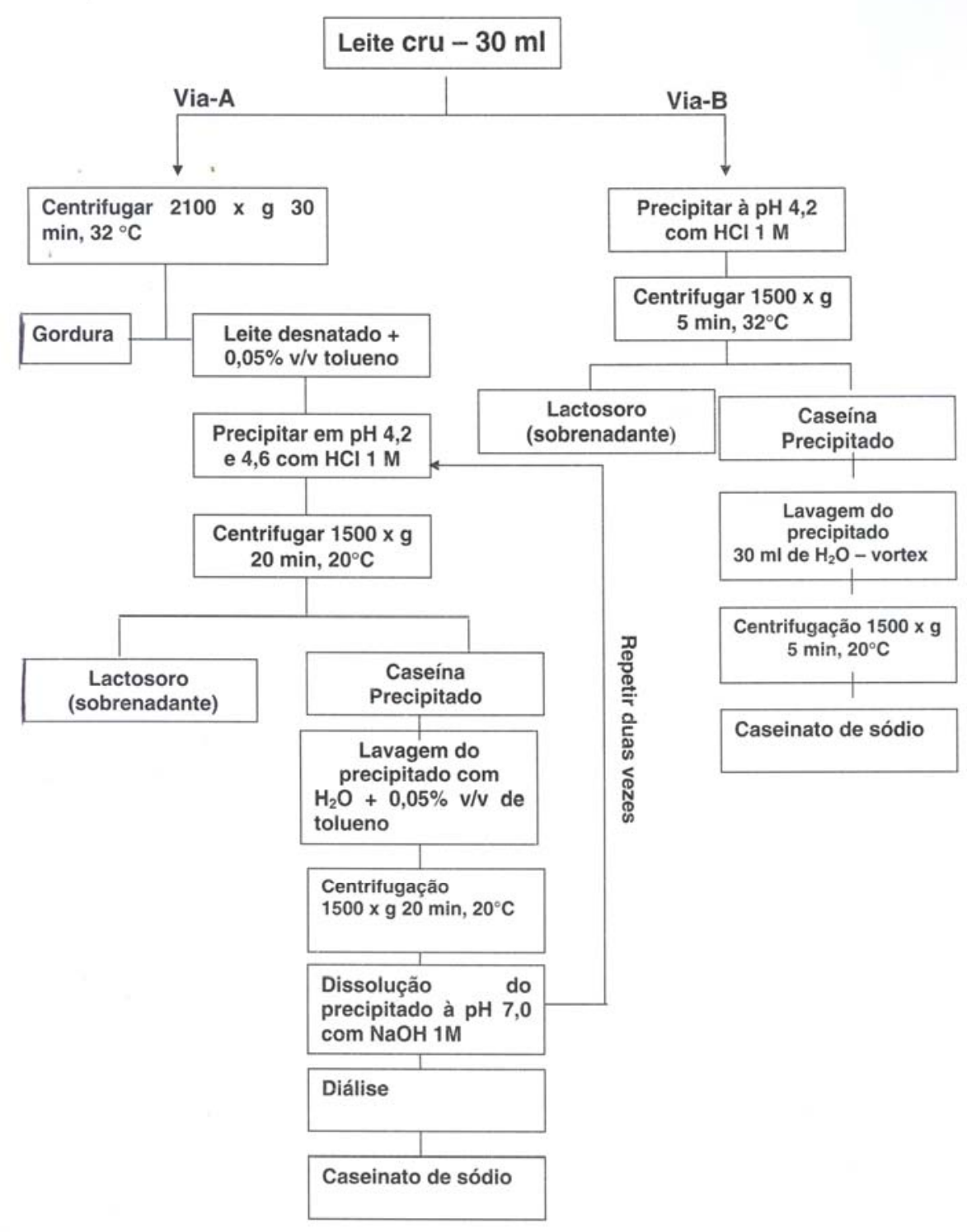

Figura 1. Protocolo de isolamento do caseinato de sódio. Via A- protocolo tradicional utilizado para obtenção de caseinato do leite de égua, vaca, humano, cabra, porca e camela; Via B- nova via proposta para separação do caseinato do leite de cabra fraudado com leite de vaca.

Observa-se que cada espécie possui um perfil de uréia-PAGE característico, como uma impressão digital, e é mais difícil distinguir os perfis de SDS-PAGE, provavelmente, pelo fato de as caseínas das espécies estudadas possuírem massas moleculares próximas (Fig. 2B). O método uréia-PAGE foi o mais apropriado para a detectação do leite de vaca, não só no leite de cabra, mas, também, no leite de outras espécies estudadas, pela migração rápida da caseína $\alpha_{\mathrm{S} 1}$ bovina. O perfil eletroforético das caseínas das diversas espécies, separados pelo SDS-PAGE (Fig. 2B), mesmo com a proximidade entre bandas, poderia servir para detectar a fraude do leite de égua adicionado de leite de cabra ou de vaca, pois as caseínas $\beta$ e $\kappa$ das duas espécies apresentam peso molecular menor que o da caseína do leite de égua, resultando em uma migração mais rápida. Essa técnica pode ser uma alternativa para o controle da qualidade do leite de éguas nas regiões que o produzem para comercialização, a exemplo de alguns países 
europeus como França e Alemanha, ou na Ásia Central, onde o rebanho eqüino é mais numeroso que o bovino. Nesses países, o leite de égua pode ser uma alternativa para substituir o humano para o lactante, tendo em vista a semelhança na composiçao do leite dessas duas espécies (Morais et al., 1999; Egito et al., 2001b). Esses métodos eletroforéticos poderiam também ser utilizados para verificar a qualidade da proteína, principalmente em leites especiais como o humano. No leite, mesmo após os processos de conservação, como pasteurização, esterilização e liofilização, enzimas como a plasmina podem alterar suas características sensoriais e físicoquimicas, como a degradação da caseína eqüina, estocada a $7^{\circ} \mathrm{C}$ por dois anos, com o aparecimento da caseína do tipo $\gamma$, resultante da hidrólise da $\beta$ caseína pela plasmina (Egito et al., 2003).
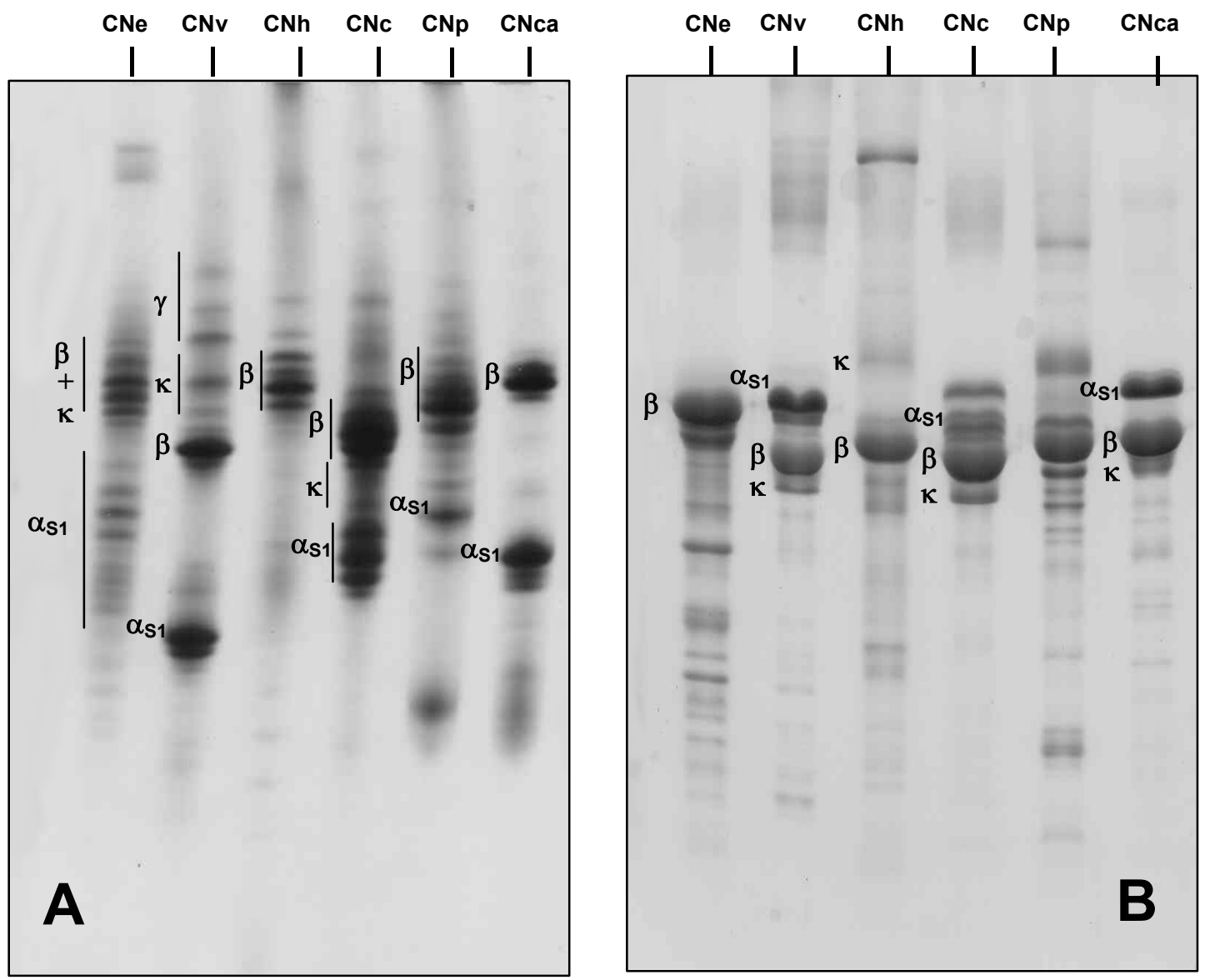

Figura 2. Comparação eletroforética das caseínas de alguns mamíferos poligástricos e monogastricos. Uréia PAGE (A) e SDS-PAGE (B) do caseinato de sódio procedente do leite de diferentes mamíferos. Depositaramse $20 \mu \mathrm{l}$ de proteínas $(2 \mathrm{mg} / \mathrm{ml})$ em cada poço, revelado com azul de Coomassie. Quando as bandas são conhecidas, o tipo de caseína é indicado ao lado $\left(\alpha_{\mathrm{s} 1}, \beta, \kappa\right.$ ou $\left.\gamma\right)$. CNe, caseína de égua; $\mathrm{CNv}$, caseína de vaca; $\mathrm{CNh}$, caseína humana; $\mathrm{CNc}$, caseína de cabra; $\mathrm{CNp}$, caseína de porca; $\mathrm{CNca}$, caseína de camela.

A Fig. 3 mostra o perfil eletroforético das amostras resultantes da simulação de adulteração do leite de cabra com o leite de vaca. O leite de cabra puro apresentou uma banda de coloração mais intensa de $\beta$-caseína que o leite de vaca (Fig. 3, linhas A e H) e em ambos os casos ocorreu migração eletroforética similar. No entanto, a caseína $\alpha_{\mathrm{S} 1}$ caprina apresentou menor mobilidade eletroforética que a bovina, possibilitando como foi mostrado na Fig. 2, a detecção da adulteração do leite de cabra com leite de vaca. Na caseína caprina (Fig. 3, linha A), não há bandas com mobilidade eletroforética similares à $\alpha_{S 1}$-caseína bovina (linha $\mathrm{H}$ ). No 
entanto, com o incremento da adulteração do leite de cabra com o leite de vaca, de 2,5 para 25\% (Fig. 3, linhas D a G), uma banda com mobilidade eletroforética similar à $\alpha_{\mathrm{S} 1}$-caseína bovina intensificou-se a partir do aumento da concentração do leite de vaca. Portanto, pode-se detectar leite de vaca no leite de cabra, quando a proporção daquele for $2,5 \%$ ou mais, pela eletroforese uréia-PAGE utilizando-se azul de Coomassie. Isto ocorre tanto no método tradicional, onde a revelação ocorre em, aproximadamente, $12 \mathrm{~h}$, como no rápido (30 min), com o aquecimento dos géis. Furtado (1983), ao usar o método uréia-PAGE, evidenciou a presença de fraude a partir de $5 \%$ de leite de vaca no leite pasteurizado de cabra. Outros métodos eletroforéticos, como a eletroforese capilar e a IEF, foram utilizados para detectar diferentes tipos de leite em misturas de leite de vaca, ovelha
1996). Cada tipo de leite originou um perfil eletroforético típico, permitindo a sua identificação. O método utilizado por Cattaneo et al. (1996) permitiu a detecção de $8 \%$ de leite de vaca adicionado ao leite de ovelha e cabra, de acordo com diferentes tempos de migração da $\alpha_{\mathrm{S} 1}$-caseina de cada espécie. Cartoni et al. (1999), ao utilizarem a mesma técnica dos autores citados, para determinar a adulteração de produtos de leite de cabra com leite de vaca com base na presença da $\alpha$-lactalbumina e $\beta$ lactoglobulina A e B, detectaram $2 \%$ de leite de vaca na mistura dos dois tipos de leite e $4 \% \mathrm{em}$ queijos. A detecção de $1 \%$ do leite de vaca adicionado ao leite de cabra é possível quando se utiliza o método oficial da Comunidade Européia, por detecção das caseínas- $\gamma_{2}$ e $-\gamma_{3}$ por IEF (Reference..., 1996). e cabra (Cattaneo et al., 1996; Reference...,

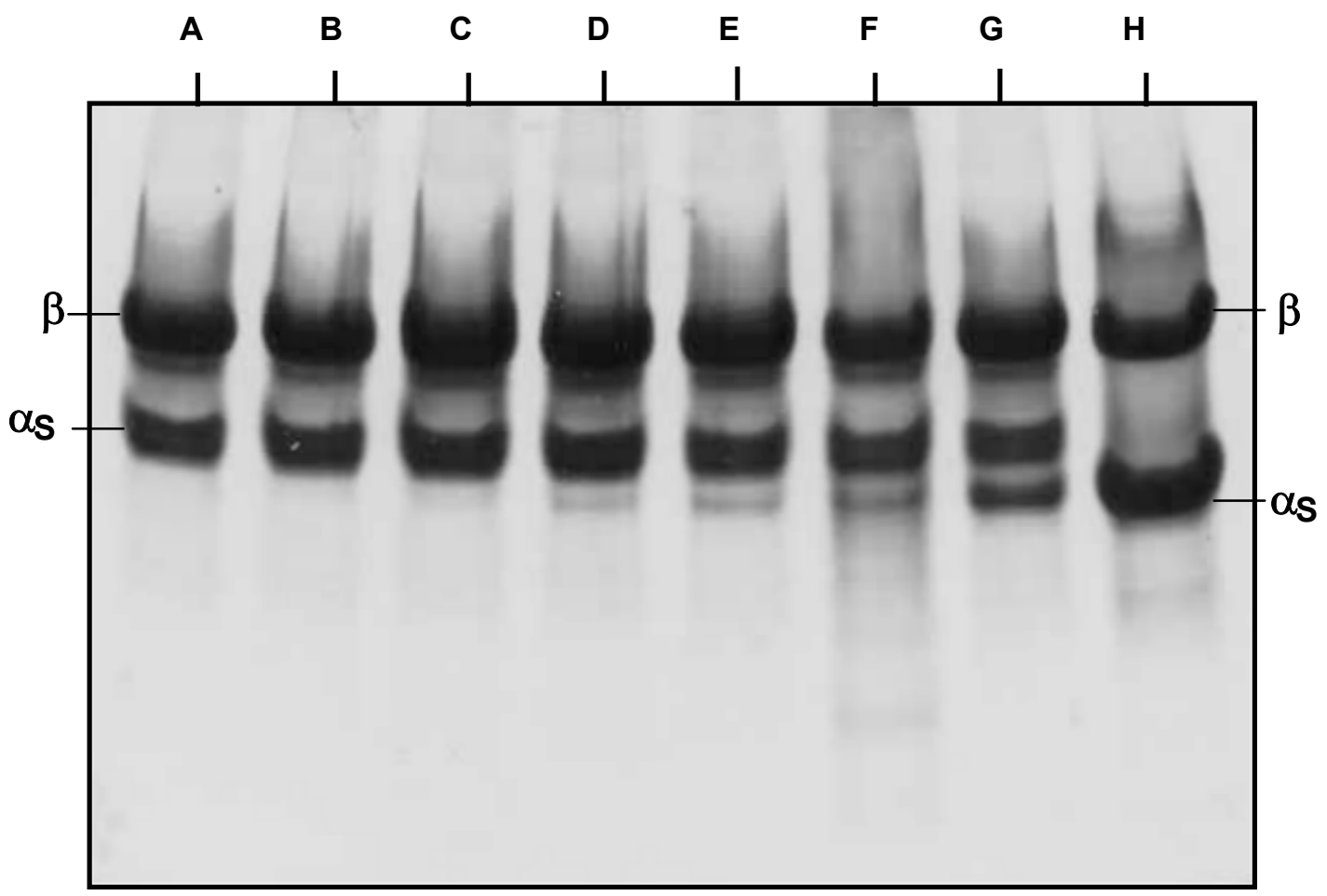

Figura 3. Perfil eletroforético (uréia-PAGE) da simulação de fraude do leite de cabra com leite de vaca. (A) $100 \%$ de leite caprino, $(\mathrm{H}) 100 \%$ de leite bovino e misturas contendo $0,5 \%$ (B), $1 \%$ (C), $2,5 \%$ (D), $5 \%(\mathrm{E}), 10 \%(\mathrm{~F}), 25 \%(\mathrm{G})$ de leite bovino.

\section{CONCLUSÕES}

Uréia-PAGE é um método eficiente para identificação de adulteração do leite de cabra com leite de vaca. A modificação do método referente à preparação e à separação das caseínas, bem como coloração rápida com aquecimento do gel, possibilitou a obtenção de resultado rápido e seguro. Uréia-PAGE e SDSPAGE poderão ser usadas para identificação de fraudes do leite de égua. 


\section{AGRADECIMENTOS}

Os autores agradecem a Osmarilda Machado, João Ricardo, Jorge Silvestre e José Tabosa técnicos do Laboratório de Tecnologia de Leite da Embrapa-Caprinos, pela colaboração na preparação de soluções e géis e à Dra. Mariza Barbosa (Diretora Executiva da Embrapa), Ana Brasileiro e Elisio Contini (Pesquisadores da Embrapa Labex-França), pelo incentivo na realização da colaboração com a URAFPA na França.

\section{REFERÊNCIA BIBLIOGRÁFICAS}

ADDEO, F.; MOIO, L.; CHIANESE, L. et al. Use of plasmin to increase the sensitivity of the detection of bovine milk in cheese by gel isoelectric focusing of $\gamma_{2}$-caseins. Milchwissenschaft, v.45, p.708-711, 1990.

ANGUITA, G.; MATIN, R.; GARCIA, T. et al. Immunostick ELISA for detection of cows' milk in ewes' milk and cheese using a monoclonal antibody against bovine $\beta$-casein. J. Food Protect., v.59, p.436-437, 1996.

ANGUITA, G.; MATIN, R.; GARCIA, T. et al. Indirect ELISA for detection of cows' milk in ewes' and goat milks using a monoclonal antibody against bovine $\beta$-casein. J. Dairy Res., v.62, p.655-659, 1995.

CARTONI, G.; COCCIOLI, F.; JASIONWSKA, $\mathrm{R}$. et al. Determination of cow's milk in goats' milk and cheese by capillary electrophoresis of whey protein fractions. J. Chromatogr. A., v.846, p.135-141, 1999.

CATTANEO, T.M.P.; NIGRO, F.; GREPPI, G.F. Analysis of cows', goats' and ewes' milk mixtures by capillary zone electrophoresis (CZE): preliminary approach., Milchwissenschaft, v.51, p.616-619, 1996.

EGITO, A.S.; GIRARDET, J.M.; MICLO, L. et al. Highly sensitive periodic acid/Schiff detection of bovine milk glycoproteins electrotransferred after nondenaturing electrophoresis, urea electrophoresis, and isoelectric focusing. Lait, v.81, p.775-785, 2001a.

EGITO, A.S.; GIRARDET, J.M.; MICLO, L. et al. Susceptibility of equine $\kappa$ - and $\beta$-casein to hydrolysis by chymosin. Int. Dairy J., v.11, p.855-893, 2001b.

EGITO, A.S.; GIRARDET, J.M.; POIRSON, C. et al. Action of plasmin on equine $\beta$-casein. Int. Dairy J., v.13, p.813-820, 2003.

EGITO, A.S.; MICLO, L.; LOPEZ, C. et al. Separation and characterization of mare's milk $\alpha_{\mathrm{s1}}{ }^{-}, \beta-{ }^{-}, \kappa$-caseins, $\gamma$-casein-like, and proteose peptone component 5-like peptides. J. Dairy Sci., v.85, p.697-706, 2002.

FURTADO, M. Detection of cow milk in goat milk by polyacrylamide gel electrophoresis. $J$. Dairy Sci., v.66, p.1822-1824, 1983.

HERRERO-MARTINEZ, J.M.; SIMOALFONSO, E.F.; RAMIS-RAMOS, G. et al. Determination of cow's milk in non-bovine and mixed cheeses by capillary electrophoresis of whey protein in acidic isoelectric buffers. $J$. Chromatogr., A. v.878, p.261-271. 2000.

KAMINARIDES, S.E.; ANIFANTAKIS, E.M. Comparative study of the separation of casein from bovine, ovine and caprine milks using HPLC. J. Dairy Res., v.60, p.495-504, 1993.

LAEMMLI, U.K.; FAVRE, M. Maturation of the head of bacteriophage T4. I. DNA packaging events. J. Mol. Biol., v.80, p.575-599, 1973.

LAEZZA, P.; NOTA, G.; ADDEO, F. Determination of bovine and ovine milk in mixtures by fast ion-exchange chromatography of whey protein. Milchwissenschaft, v.46, p.559$561,1991$.

LAW, A.J.R.; PAPOFF, C.M.; DALGLEISH, D.G. et al. Quantitative fraction of ovine casein by cation-exchange FPLC. Milchwissenschaft, v.47, p.279-282., 1992.

LAW, A.J.R.; TZIBOULA, A. Quantitative fractionation of caprine casein by cationexchange FPLC. Milchwissenschaft, v.47, p.558$562,1992$.

MAUDET, C.; TABERLET, P. Detection of cow' milk in goats' cheeses inferred from mitocondrial DNA polymorphism. J. Dairy Res., v.68, p.220-235, 2001

MAYER, W.; HORTNER, H. Discontinuous electrophoresis of $\beta$-caseins for the determination of bovine caseins in milk and dairy products. Electrophoresis, v.13, p.803-804. 1992. 
MOLINA, E.; FRUTOS, M.; RAMOS, M. Capillary electrophoresis characterization of the casein fraction of cheeses made from cows', ewes' and goats' milk. J. Dairy Res., v.67, p.200-216, 2000.

MOLINA, E.; MARTIN-AVAREZ, P.J.; RAMOS, M. Analysis of cows', ewes' and goats' milk mixtures by capillary electrophoresis: quantification by multivariate regression analysis. Int. Dairy J., v.9, p.99-105, 1999.

MONTAGNE, P.M.; TREGOAT, V.S.; CUILLIERE, M.L. et al. Measurement of nine human milk proteins by nephelometric immunoassays: application to the determination of mature protein profile. Clin. Biochem., v.33, p.181-186, 2000.

MORAIS, M.T.; SIMONE, E.M.; ROMANO, L.A. Estudo da composição do leite de égua e comparação com o leite de mulher. Hig. Alim., v.13, p.62-68, 1999.

PELLEGRINO, L.; DE NONI, I.; TIRELLI, A. et al. Detection of cows' milk in non-bovine cheese by HPLC of whey proteins. Note 1: Application to water buffalo Mozzarella cheese. Sci. Tec. Lattiero-Casearia, v.42, p.87-101, 1991.

REFERENCE method for the detection of cows' milk and caseinate in cheeses from ewes' milk, goats' and buffalos' milk or mixtures of ewes' goats' and buffalos' milk. EEC N ${ }^{\circ} 1081 / 96$ of 14 june 1996. Off. J. Eur.opean Commun., v.142, p.15-25, 1996.

ROLLAND, M.P.; BITRI, L.; BENSANÇON, P. Mono-specificity of the antibodies to bovine $\alpha_{\mathrm{S}^{-}}$ casein fragment 140-149: application to the detection of bovine milk in caprine dairy products. J. Dairy Res., v.62, p.83-88. 1995

SANOGO, T.; PÂQUET, F.; AUBERT, G. et al. Purification of $\alpha_{\mathrm{S} 1}$-casein by fast protein liquid chromatography. J. Dairy Sci., v.72, p.22422246, 1989.

VISSER, S.; JENNESS, R.; MULLIN, R.J. Isolation and characterization of $\beta$ - and $\gamma$-casein from horse milk. Biochem. J., v.203, p.131-139, 1982. 